\title{
Os Referenciais Curriculares Municipais para a Educação Infantil de Natal, RN, e as relações com a Base Nacional Comum Curricular: um olhar para a dança na infância
}

\author{
Carolina Romano de Andrade \\ Universidade Estadual Paulista Júlio de Mesquita Filho (Unesp)
}

\begin{abstract}
Resumo
Este artigo expõe um olhar sobre o tipo de dança que está sendo oferecida à Educação Infantil (El) por meio de uma leitura dos Referenciais Curriculares para a Educação Infantil de Natal, Rio Grande do Norte, e da Base Nacional Comum Curricular (BNCC) - Educação Infantil. Parte-se do pressuposto que a dança é um campo do conhecimento que relaciona experiências corporais, artísticas e estéticas. O panorama obtido por esse estudo apresenta um retrato das transições advindas da BNCC no que tange a dança na Educação Infantil. Essa leitura permitiu observar que os pressupostos presentes na BNCC e no documento de Natal dialogam, ainda que não efetivamente, com as proposições de artísticas/pedagógicas em dança. Dessa maneira, são apresentadas possibilidades de inserção da dança nos documentos curriculares por meio dos direitos, campos de experiências e objetivos de aprendizagem e desenvolvimento, conforme disposto na BNCC.
\end{abstract}

Palavras-chave: Dança. Educação Infantil. Currículo. Natal.

Esse artigo ${ }^{1}$ traça um olhar para dança na infância por meio das proposições advindas da Base Nacional Comum Curricular da Educação Infantil (BNCCEI-2017) e dos Referenciais Curriculares Municipais para a Educação Infantil de Natal (documento provisório, RCMEINATAL). Ademais, apresenta características conceituais, de organização e finalidade dos documentos, oferecendo uma possibilidade de inserção dos conhecimentos em Dança ${ }^{3}$ nos documentos curriculares da Educação Infantil.

Para tanto, este artigo está organizado em três partes, a primeira faz um percurso retrospectivo da Educação Infantil por meio da legislação, expondo as mudanças ocorridas

\footnotetext{
1 Esse artigo é parte da pesquisa de pós-doutorado em andamento, desenvolvida no Programa de PósGraduação em Artes Cênicas (PPGArC), Universidade Federal do Rio Grande do Norte (UFRN). A pesquisa possui financiamento do Programa Nacional de Pós-Doutorado da Capes (PNPD/CAPES). 2 Para este artigo convencionaremos utilizar a sigla BNCCEI, quando nos referimos a parte específica da Base Nacional Comum Curricular que trata da Educação Infantil. A construção da BNCC (da Educação Infantil e Fundamental) ocorreu em etapas que incluíram três versões do documento, elaboradas entre 2015 e dezembro de 2017. A base referente ao Ensino Médio foi publicada em 2018. 30 conhecimento em Dança é revelado pelo conhecimento historicamente construído pela dança, que engloba as Temáticas da Dança (ANDRADE; GODOY, 2018), entre as quais: o conhecimento do corpo, fundamentos da dança (relações dançadas de peso, espaço, ritmos e tempos) e os processos de criação em dança do indivíduo, coletivo, do mundo histórico e socialmente construído.
} 
entre os principais documentos nacionais relacionados à infância (Referencial Curricular de Educação Infantil- RCNEI de 1998, Diretrizes Curriculares Nacionais para a Educação InfantilDCNEI $^{4}$ de 2010 e a BNCCEI de 2017).

A segunda apresenta o documento curricular provisório de Natal e as relações com a BNCCEI. Por essa opção, destacamos a importância da apreciação de um referencial que se encontra em caráter preliminar. Ressaltamos que o documento da capital potiguar esteve aberto para consulta pública no site da prefeitura de $\mathrm{Natal}^{5}$ para contribuições dos professores do município que serão consideradas pelo município e equipe de revisores antes da publicação da versão final ${ }^{6}$.

A intenção é revelar as premissas do documento, pois ele pretende garantir ao munícipio de Natal os pressupostos presentes na Base em acordo com o contexto da capital potiguar. Outrossim, o RCMEI-NATAL destaca o caráter de provisoriedade de um documento curricular como uma característica pois, "[...] toda produção dessa natureza é passível de revisão e atualização e a construção colaborativa, com a participação dos profissionais que se dedicam à Educação Infantil" (NATAL, 2017, p. 07).

Dessa maneira, entendemos que as sugestões apontadas por esse artigo possam vir a colaborar com futuras modificações do documento no que tange as possibilidades de inserção conhecimentos em Dança na Educação Infantil (El).

Neste artigo, preocupa-nos discutir a BNCCEI e o documento curricular para a Educação Infantil de Natal, RN, em associação com proposições artísticas/pedagógicas em Dança. Isto posto, não estamos preocupados com sugestões de atividades ou prescrições de modelos a serem seguidos, mas a intenção é observar e sugerir para os documentos curriculares como os conhecimentos em Dança podem estar nos currículos por sua potencialidade artística/pedagógica. Dessa maneira, na terceira parte apresentamos uma proposição curricular de como tais conhecimentos poderiam ser articulados aos direitos,

4 No ano de 2013, ocorreu uma revisão nas DCNEl de 2010 por meio do documento Diretrizes Curriculares Nacionais para a Educação Básica (2013). Esta revisão incorpora os avanços presentes na política, na produção científica e nos movimentos sociais na área da infância. Em relação à dança para El este documento reforça o que apresenta as DCNEI (2010) e sugerem na organização das experiências de aprendizagem das propostas curriculares, atividades que promovam uma sensibilização à dança e desenvolvam a expressão motora e modos da criança perceber seu próprio corpo.

5 O documento que compõe esse artigo foi disponibilizado mediante solicitação por e-mail pela Secretaria de Educação de Natal, RN.

6 No momento da escrita desse artigo (julho e agosto de 2020) todo o Brasil encontra-se em quarentena devido à pandemia ocasionada pela Covid-19. Entramos em contato com o Departamento de Educação Infantil (DEI) da Prefeitura Municipal de Natal, RN, a fim de perguntar sobre a data de publicação e as possíveis alterações do documento preliminar. Foi-nos informado que a organização e os capítulos não sofrerão alterações significativas, já que as contribuições da consulta pública foram pontuais e não se referem a estrutura. A Secretaria Municipal de Educação declarou que a equipe de educação inclusiva realizou um parecer pedindo algumas modificações no que tange a matéria que serão atendidas, bem como as sugestões da consulta pública. Dessa maneira, a previsão de publicação é para até o fim do ano de 2020, no entanto essa data pode se alterar devido ao contexto de pandemia. 
campos de experiência e objetivos de aprendizagem desenvolvimento referenciados na Base e no documento da capital potiguar.

\section{O caminho da legislação para educação infantil: as concepções de currículo, criança e dança.}

[...] quanto mais puxarmos a borracha do estilingue para trás mais longe lançaremos a pedra para frente" (BARBOSA, 2015a, p.221).

Olhar para o passado nos auxilia a entender o momento presente e nos dá subsídios para projetar o futuro. Sob essa ótica, apresentaremos um percurso nas leis e documentos a fim de compreendemos o que hoje conhecemos por Educação Infantil. Cientes de nossa limitação em abordar a legislação em sua totalidade, faremos um recorte nas normatizações que contribuíram para a regulamentação da El a partir da constituição federal de 1988. Isto porque, a carta magna brasileira de 88 reconheceu pela primeira vez a El como direito da criança e dever do Estado, passando a integrar a política nacional de educação, com ofertas de gratuidade e atendimento obrigatório em creches, conforme disposto no art. 208, item I e IV (BRASIL, 1988). Outro marco regulatório aconteceu no ano de $1990 \mathrm{com}$ a publicação do Estatuto da Criança e do Adolescente (ECA) que firma no capítulo IV, artigo 54, inciso IV: "É dever do Estado assegurar [...] atendimento em creche e pré-escola às crianças de zero a seis anos de idade (ECA, 1990)". E no ano de 1996 a Lei de Diretrizes e Bases da Educação (LDB) 9394/96 legitimou a Educação Infantil como primeira etapa da educação básica, apresentando como objetivo o desenvolvimento integral da criança em seus aspectos psicológico, intelectual, social e físico e com caráter de obrigatoriedade a partir dos 4 (quatro) anos de idade?

A partir da LDB 9394/96 outros documentos ${ }^{8}$ foram importantes para a definição de um campo para a infância, com pressupostos conceituais e curriculares relacionados à Educação Infantil entre os quais: o Referencial Curricular de Educação Infantil - RCNEI (1998), Diretrizes Curriculares Nacionais para a Educação Infantil - DCNEI (2010) e o mais recente deles a Base Nacional Comum Curricular (2017), a partir desses dois últimos é que se fundamentam as perspectivas curriculares atuais para a educação na infância.

Diante do exposto, vale ressaltar três aspectos para o entendimento das concepções curriculares vigentes que repercutem nas possibilidades da inserção dos conhecimentos em

7 Essa obrigatoriedade foi dada em 4 de abril de 2013 pela alteração da LDB, por meio da Lei 12.796 . 8 Muitos documentos fazem parte do escopo de regulamentação da Educação Infantil, entre os quais Parâmetros Nacionais de Qualidade para a Educação Infantil, v. 01 e 02, Parâmetros Básicos de Infraestrutura para Instituições de Educação Infantil, Plano Nacional de Educação - PNE (2001), Política Nacional de Educação Infantil I (2006), entre outros que não serão abordados neste artigo por não tratarem especificamente dos aspectos curriculares. 
Dança e por sua vez refletem nas práticas artísticas/pedagógicas de Dança na infância, que discutiremos adiante desse artigo.

O primeiro é que a partir das Diretrizes Curriculares Nacionais para a Educação Infantil DCNEI (2010) se apresenta uma mudança significativa de abordagem para a infância. Neste documento a criança se torna o centro do processo de aprendizagem, como sujeito histórico e de direitos que nas interações e práticas do dia a dia "[...] constrói sua identidade pessoal e coletiva, brinca, imagina, fantasia, deseja, aprende, observa, experimenta, narra, questiona e constrói sentidos sobre a natureza e a sociedade, produzindo cultura (BRASIL, 2010, p. 12)".

Anteriormente no RCNEI (1998) o foco estava no desenvolvimento integral da criança, mas em uma perspectiva em que os estímulos eram oferecidos pelos adultos, lê-se em Brasil: "É o adulto, na figura do professor, portanto, que, na instituição infantil, ajuda a estruturar o campo das brincadeiras na vida das crianças (1998, p.28)".

Nesse sentido, no RCNEI a construção de conhecimento no processo de aprendizagem e desenvolvimento da criança tem o enfoque tanto no sujeito quanto na interação social, o que revela influências de abordagens construtivistas estudadas por autores como Jean Piaget (1970, 1971, 1975, 1976, 1978), Lev Semionovitch Vygotsky $(1979,1984)$ e Henry Wallon (1979).

Por sua vez, nas DCNEI a sociologia da infância9 ${ }^{9}$ é um campo teórico a ser desbravado na EI na direção de enfatizar as crianças como seres sociais. Esta perspectiva reconhece a criança como parte da sociedade, portanto atuante nas transformações sociais. "Esta inflexão permite pensar a criança como sujeito e ator social do seu processo de socialização, e também construtores de sua infância, como atores plenos, e não apenas como objetos passivos deste processo e de qualquer outro (ABRAMOWICZ; OLIVEIRA, 2010, p.42)". Nesse sentido, uma esteira de autores nos revela esses pressupostos: Alan Prout (2010), Gilles Brougère (1995, 1998, 2002), Jens Qvortrup (1993), Jorge Larrosa (2004,2010), Loris Malaguzzi (1994), Manuel Sarmento (2005, 2011), Régine Sirota (2001), William Corsaro (1990, 2005a, 2005b), entre outros, que permeiam esse novo olhar para a infância. A BNCCEI vai ao encontro dessas concepções de criança em acordo com o que foi proferido nas DCNEI (2010).

O segundo aspecto aborda a natureza de cada documento e sua organização curricular. O RCNEI (1998) é um referencial de caráter não obrigatório que tem como objetivo “[...] subsidiar os sistemas educacionais, que assim o desejarem, na elaboração ou implementação de programas e currículos condizentes com suas realidades e singularidades (BRASIL, 1998, p. 13)". Este documento é voltado para os profissionais que atuam com crianças e aponta

9 Vale destacar que não existe apenas um enfoque da sociologia da infância, mas uma intenção dos estudiosos em desenvolver um olhar para as crianças numa perspectiva social que a reconhece como parte da sociedade. 
caminhos para reflexão educacional distribuídos em três volumes, em uma perspectiva de instrumentalização do processo educativo. Existe uma separação etária para as orientações (0-3 anos, creche, e 4-6 anos, pré-escola) que estão consolidadas em duas esferas de experiências: 1) Formação Pessoal e Social; 2) Conhecimento de Mundo, composto pelos eixos, Identidade e autonomia, Movimento, Artes visuais, Música, Linguagem oral e escrita, Natureza e sociedade, e Matemática.

Nesse sentido, as propostas pedagógicas da El estão organizadas por eixos de trabalho e cada um deles possui objetivos, conteúdos, orientações didáticas gerais e bibliografia para os professores.

Ao observar essa disposição entendemos que o documento apesar de propor uma integração dos conhecimentos apresenta uma organização curricular com resquícios de uma noção escolarizante para a infância. Esse documento ainda utiliza a nomenclatura de préescola que é amplamente criticada por estudiosos da infância que evidenciam que a Educação Infantil não é uma preparação para um vir a ser, ou seja não é uma habilitação para a "verdadeira" fase escolar. Outrossim, nos revela uma fragmentação por áreas do conhecimento, semelhante ao disposto no ensino fundamental, reforçando a El como uma preparação para a etapa que segue. Nesse sentido, os eixos desse documento encontramse em função de atender uma necessidade de categorização do mundo do adulto e vão de encontro à perspectiva que entende o mundo da criança por sua inteireza e não o divide em assuntos, disciplinas e categorias.

Por sua vez, as Diretrizes Curriculares Nacionais para a Educação Infantil é um documento normativo de caráter obrigatório e tem a finalidade de orientar as políticas, elaboração e acompanhamento (planejamento e avaliação) de propostas pedagógicas e curriculares para a El.

As DCNEl estabelecem os princípios éticos, estéticos e políticos como basilares para guiar o trabalho na Educação Infantil. Os eixos que norteiam o currículo são as interações e a brincadeira. As práticas pedagógicas devem "[...] ter como objetivo garantir à criança acesso a processos de apropriação, renovação e articulação de conhecimentos e aprendizagens de diferentes linguagens (BRASIL, 2010, p.18)". Para este documento, o currículo é um "[...] conjunto de práticas que buscam articular as experiências e os saberes das crianças com os conhecimentos que fazem parte do patrimônio cultural, artístico, ambiental, científico e tecnológico, de modo a promover o desenvolvimento integral de crianças de 0 a 5 anos de idade" (p. 12).

Isto posto, as DCNEI defendem que o currículo promova as diversas linguagens da infância e a sua apropriação deve ocorrer de maneira integrada e articulada às experiências cotidianas das crianças fomentando a indivisibilidade das "[...] dimensões expressivomotora, afetiva, cognitiva, linguística, ética, estética e sociocultural da criança (ibid, p. 19)”. Nesse 
sentido, as políticas, as instituições e os professores necessitam garantir aos pequenos o direito de se apropriar de tais experiências e saberes. Esse documento desloca a centralidade do currículo do professor para a criança, a fim de atender as perspectivas da integralidade da aprendizagem na infância.

Por sua vez, a BNCC (Base Nacional Comum Curricular) é o documento que delibera sobre as aprendizagens essenciais ao longo da Educação Básica, garantindo os direitos de aprendizagem e desenvolvimento, de acordo Plano Nacional de Educação (BRASIL, 2017). Cabe destacar que a BNCC não se trata de um currículo, mas servirá de subsídio para que Estados, municípios e escolas elaborem seus referenciais, propostas, orientações curriculares e projetos políticos pedagógicos (PPP), de acordo com cada contexto e levando em conta as perspectivas apresentadas na Base. Esse documento apresenta sua organização por 10 competências gerais para a educação básica ${ }^{10}$, que para tal inclui a mobilização de conhecimentos (conceitos e procedimentos) e habilidades (prática, cognitiva e socioemocional), atitudes e valores, focadas na vida cotidiana, na construção da cidadania e do trabalho (BRASIL, 2017). Essa última proposição traz a luz uma discussão a respeito do caráter neoliberal da Base, que em muitos momentos pensa a educação como uma preparação para o mercado de trabalho. Apesar disso, a parte da Base que se refere especificamente a El, não está focada no caráter do trabalho e na preparação do vir a ser, mas na possibilidade de a criança vivenciar suas experiências em sua inteireza, considerando a construção de saberes baseadas no cotidiano da infância articulados aos campos de experiência.

Desse modo, a BNCCEI amplia a relação curricular já vista nas DCNEI (em acordo com o Art. 9. da Resolução no 5, de 17 de dezembro de 2009), reafirma os eixos estruturantes das práticas pedagógicas interações e a brincadeira e acrescentam que o currículo é "[...] um conjunto de práticas que articulam os saberes e os fazeres das crianças com os conhecimentos já sistematizados pela humanidade (BRASIL, 2017)". Para tanto, propõe uma integração curricular na Educação Infantil, a partir dos eixos norteadores das DCNEI ${ }^{11}$, considerando os seis direitos de aprendizagem e desenvolvimento (Conviver; Brincar; Participar; Explorar; Expressar; Conhecer-se) e os cinco campos de experiências para a EI (O eu, o outro e o nós; Corpo, gestos e movimentos; Traços, sons, cores e formas; Escuta, fala, pensamento e imaginação; Espaços, tempos, quantidades, relações e transformações), em que estão determinados objetivos em três grupos por faixa etária: bebês ( 0 a 1 ano e 6 meses), crianças bem pequenas ( 1 ano e 7 meses a 3 anos e 11 meses) e crianças pequenas ( 4 anos a 5 anos e 11 meses).

10 As 10 competências gerais da base se referem a: conhecimentos, pensamento científico, crítico e criativo, diversidade cultural, comunicação, cultura digital, trabalho e projeto de vida, argumentação, autoconhecimento, cooperação, empatia, responsabilidade para consigo e com o outro e cidadania (Brasil, 2017).

$11 \mathrm{Na}$ BNCC os eixos norteadores são chamados de eixos estruturantes. 
A organização por campos de experiências foi inspirada nas Indicações Nacionais Curriculares italianas de 2012 (FINCO; BARBOSA; FARIA, 2015). Os campos não seriam uma aproximação da divisão por áreas do conhecimento, linguagens ou componentes curriculares, mas uma perspectiva voltada a centralidade do cotidiano da criança, levando em conta seus saberes em articulação com os conhecimentos socialmente construídos pela humanidade (BARBOSA; RICHTER, 2015b). Nesse sentido, os campos de experiência tratam de uma possibilidade de arranjo curricular que apresenta zonas de conhecimento, que englobam o conhecimento sócio-histórico, as múltiplas linguagens e as práticas sociais, para que adultos e crianças articulem na sua jornada cotidiana de aprendizagem.

Melo et al. (2016) consideram a divisão por campos de experiência um avanço no modo de organização do trabalho pedagógico na El. Isto porque, apesar do RCNEI se atentar para a integração curricular, a BNCC aprimora a ideia de integração de conhecimentos ao ir ao encontro da concepção de infância que coloca a criança no centro da construção do conhecimento. Ao destacar os eixos (interações e a brincadeira) e os campos experiências como foco do processo de aprendizagem se "desloca do que se passa para as crianças, para o que se passa com e entre elas" (p. 137). Dessa maneira, a intenção é que os cinco campos de experiência sejam trabalhados de forma integrada nas práticas pedagógicas cotidianas da infância.

O terceiro e último aspecto para o entendimento das concepções curriculares vigentes em relação à proposição desse artigo, aborda as modificações sobre a dança na infância a partir do RCNEI. Nesse documento a linguagem da Dança está inserida no eixo Movimento, em dois blocos: Expressividade e Equilíbrio e Coordenação, pertencentes à esfera da experiência Conhecimento de Mundo.

No primeiro bloco a dança é colocada junto às práticas esportivas, jogos e brincadeiras com a finalidade de ampliar as capacidades comunicativas e expressivas ligadas à cultura corporal. O segundo bloco apresenta a dança entre os aspectos da motricidade incluindo as relações do ato motor, desenvolvimento físico e cognitivo da criança. Diante do exposto e segundo Mello et al (2016) o RCNEI ainda apresenta um caráter instrumental do corpo/movimento, em que a função primordial é oferecer suporte para futuras aprendizagens. Cumpre dizer, que as funções motoras, afetivas e sociais, entre outras, são importantes para o desenvolvimento da criança e fazem parte da dança, mas não são seu foco principal. O mais importante é valorizar que dançando e fruindo dança a criança entra em outro universo de experiências corporais, artísticas e estéticas, que nenhuma outra linguagem pode oferecer.

No que concerne as DCNEI (2010), a dança é parte das manifestações que promovem o relacionamento e a interação das crianças. Vale ressaltar que o documento defende que é na interação com os elementos da natureza e da cultura com seus pares, o meio e os adultos, a criança recria, inventa e produz cultura. Nas DCNEI a dança é parte das experiências 
artística, estéticas, manifestação cultural e expressiva que deve ser oferecida no currículo da El juntamente com a música, artes visuais e teatro. Nota-se aqui uma mudança de concepção nas DCNEI, por esse documento a dança apresenta um enfoque artístico e estético, o que ultrapassa o caráter relacionado aos aspectos motores, socioafetivos ou de suporte para outras aprendizagens como visto no RCNEI. Dessa forma, a dança alcança uma dimensão que se aproxima das subjetividades artísticas atreladas a ela.

Por sua vez na BNCC, a dança aparece especificamente mencionada em dois campos de experiência. O primeiro, Corpo, gestos e movimentos, apresenta em seu escopo conhecer as funções do corpo na relação entre corpo, emoção e linguagem. Os objetivos que se relacionam à dança reforçam a expressão ${ }^{12}$, exploração do espaço e combinação de movimentos ${ }^{13}$ e criação ${ }^{14}$.

O segundo, Traços, sons, cores e formas, incentiva à criação de produções artísticas ou culturais, a fim de ampliar repertórios e vivências artísticas na infância. A dança é destacada no texto de apresentação do campo, mas não há menção nos objetivos de aprendizagem.

Diante do exposto, os conhecimentos em Dança deveriam permear todos os direitos e campos de experiências como parte dos conhecimentos socialmente construídos pela humanidade. Dessa maneira, a dança poderia estar presente nos objetivos de aprendizagem e desenvolvimento que serão desdobrados em práticas pedagógicas nas orientações, diretrizes e referenciais de estados, municípios e PPP escolares. Isto poderia garantir a presença da dança na infância na perspectiva de a criança poder se expressar como sujeito dialógico, criativo e sensível. E ainda proporcionar "[...] experiências ricas e diversificadas" (BRASIL, 2018, p. 30) que colaborem para ampliar o desenvolvimento integral das crianças, promovendo "[...] que todas as crianças se apropriem de diferentes linguagens e tenham disponíveis materiais para se expressar" (p. 7).

Mas, como os conhecimentos em Dança podem ser considerados entre as propostas pedagógicas na El, se não estão especificados nos documentos curriculares para a infância?

Vale evidenciar que a dança a ser trabalhada na infância é arte, expressão, experiência, movimento, fruição, cultura, linguagem e criação que abrange as produções artísticas realizadas pelas crianças, por meio do conhecimento do corpo, do espaço, do tempo, entre outros conhecimentos e saberes ${ }^{15}$ proporcionados pela dança que serão desenvolvidos na última parte desse texto.

12 Observados nos seguintes códigos da BNCC EI01CG01 e EI03CG01. Esses códigos identificam nas primeiras duas letras a etapa de Educação Infantil (EI); nos dois primeiros números a divisão por grupo de faixa etária; nas duas letras subsequentes definem o campo de experiências e os dois últimos números definem a posição da habilidade para cada grupo/faixa etária (BNCC, 2017).

13 EI02CG03.

14 EI03CG03.

15 Para Andrade e Godoy (2018) os saberes se constroem a partir da experiência em Dança, no sentido da experiencia de Larrosa (2002). Nesse aspecto, a criança que dança se apropria, (in)corpora (vive 
Para seguir surge a questão: como as especificações da BNCCEI se refletem nos Referenciais Curriculares Municipais para a Educação Infantil de Natal?

\section{O documento de Natal, RN, e suas concepções e relações com a BNCC}

Para iniciarmos esse diálogo com o documento da capital potiguar para a El, apresentamos um cenário de transição no que tange as proposições curriculares no Brasil. Primeiro destacamos que a partir da publicação da BNCC coloca-se em desuso o documento referencial curricular anterior, o RCNEI (1998). Isto porque, o Ministério da Educação (MEC) por meio da resolução CNE/CP № 2, de 22 de dezembro de 2017, que institui e orienta a implementação da Base, decidiu que todos os currículos devem se adequar a BNCC e estabelece um prazo para tal. De acordo com essa resolução, a data para que esta mudança ocorra é até 2019 e/ou início de 2020.

Embora a etapa de elaboração curricular esteja em andamento e/ou finalizada em grande parte das unidades federativas e municípios do Brasil, sabemos da diversidade de situações políticas e socioeconômicas de nossa nação e muitos locais ainda estão revendo seus documentos. Desse modo, como mencionado anteriormente, os referenciais curriculares de Natal (RCMEI) apresentam-se em fase de finalização e é sobre esse caráter de provisoriedade que debruçamos esta leitura. Reforçamos que após a publicação do RCMEI ainda se faz necessária à implantação do documento.

Isto é um processo que acontecerá a fim de que as alterações curriculares promulgadas pela $\mathrm{BNCC}$ e refletidas no $\mathrm{RCMEI}-\mathrm{Natal} / \mathrm{RN}$ cheguem às unidades escolares. Ação está que deverá abranger formações continuadas, palestras, cursos, novos modos de planejamento, entre outros esforços em conjunto com a secretária de educação, diretores, professores da rede e famílias. Outrossim, vale destacar que no atual contexto de escrita desse artigo (julho/agosto de 2020) as aulas presenciais em escolas públicas e privadas encontram-se suspensas devido a pandemia da Covid-19. As secretárias de educação, em sua maioria, estão preocupadas em distribuição de merenda escolar, organização de ensino remoto, distribuição de atividades escolares e reorganização de protocolos de volta às aulas quando possível. Diante do exposto, as finalizações de documentos curriculares e o processo de implantação da Base que estava em andamento, encontram-se temporariamente suspensos.

Dessa maneira, essa passagem entre os documentos ocorrerá ao longo dos anos com necessidade de seguidas atualizações e formações de professores. Vale lembrar que esse processo de transição também ocorreu na implementação do RCNEI em caráter nacional e

pelo corpo) o acontecimento dança e transforma a vivência em experiência, em saber (in)corporado. Nesse sentido, a experiência e a construção dos saberes em dança assim como a transposição dos conhecimentos em dança, não possuem um único formato, pois considera os envolvidos como sujeitos que possuem sua história e seus conhecimentos e estabelecem relações distintas diante das situações. 
provavelmente se repetirá na efetivação da BNCC por meio dos documentos curriculares de Estados e municípios.

Isto posto, para direcionar nosso olhar para a BNCCEI e o documento de Natal, a opção foi observar esses documentos pelo viés da sociologia da infância. Nossa intenção não foi discorrer sobre as vastas referências sobre esse tema, citadas na primeira parte desse artigo, mas defender um ponto de vista que entende as crianças como atores sociais que criam, produzem, modificam culturas, e constroem modos de significação e de atuação diferentes dos adultos.

Esse entendimento nos permite ver os campos de experiência propostos pela BNCCEI, como possibilidade de aproximar a criança da dança por meio das intencionalidades pedagógicas direcionados a essa linguagem. Sabemos que a ideia dos campos de experiência indica uma organização das aprendizagens em relação as experiências vividas na infância, distantes de qualquer caráter disciplinar e valorizando os saberes e conhecimentos fundamentais às crianças.

Dessa forma, para apresentar os Referenciais Curriculares Municipais para a Educação Infantil de Natal, destacaremos os três aspectos para o entendimento das concepções curriculares (destacados no item anterior nos documentos nacionais), são eles: 1) qual a abordagem para a criança; 2) qual a natureza do documento e sua organização curricular; 3) quais as proposições para a dança.

Respeitando essa organização, começamos com a definição de criança, assumida em Natal. Esta é produtora de cultura e sujeito de direitos, que vivencia uma etapa singular de desenvolvimento com necessidades e possibilidades pertinentes à sua "condição humana de ser biológico, histórico social e cultural" (NATAL, 2017, p. 8). Dessa forma, o documento, ao reconhecer a criança como participante e agente na construção do mundo, revela a intenção de reforçar o seu papel ativo nos seus processos de socialização. A ideia apresentada por Natal é que as crianças estabelecem seus conhecimentos nas interações aprendendo por meio das relações constituídas no meio social em que estão inseridas. Para que isto ocorra, o documento reforça que nos processos educativos haja uma intencionalidade pedagógica "com aprendizagens voltadas às necessidades, interesses e possibilidades das crianças" (p. 09). Com efeito, os referenciais curriculares para a El de Natal defendem um currículo centrado na criança e nas culturas infantis, ao mesmo tempo em que destaca para aprendizagem e o desenvolvimento da criança as contribuições das teorias: a) sociointeracionista de Piaget; b) histórico-cultural de Vygotsky; e c) psicogenética de Henri Wallon.

Dessa maneira, duas abordagens parecem atender e conviver no currículo de Natal. A primeira que se relaciona a BNCC e as DCNEI no que concerne considerar a infância como uma categoria social autônoma e a presente no RCNEl que se foca em aspectos da psicologia do desenvolvimento (Piaget), da natureza social da aprendizagem (Vygotsky) e da 
compreensão dos aspectos biológico, afetivo, social e intelectual da criança (Wallon). Isto pode ter ocorrido pela necessidade de o documento contemplar a BNCC e ao mesmo tempo incluir a opção pelas abordagens teóricas de Piaget, Vygotsky e Wallon feita pela rede municipal.

Vale ressaltar que ainda que o documento natalense seja construído por equipes diretivas, pedagogos e estudiosos da educação, em muitos momentos, se apresenta aberto a fim de acolher os diversos pensamentos de educação da rede de ensino e ao mesmo tempo cumprir as deliberações nacionais. Outrossim, os municípios têm autonomia em produzir seus currículos, porém devem respeitar as determinações da BNCC. Na medida em que o documento de Natal acolhe as prerrogativas da Base entendemos que ele contempla o documento nacional e valoriza sua autonomia na escolha das abordagens pedagógicas.

Cabe ressaltar que o documento referencial de Natal é de caráter não obrigatório com as orientações sobre a organização do trabalho de educação para a infância. A ideia principal é que o RCMEI possa auxiliar as instituições de Educação Infantil a elaborar seus projetos políticos pedagógicos (PPP), a fim de atender às orientações das bases legais. Nesse contexto, sugerem que as unidades escolares organizem seu PPP, conforme aponta a BNCC, como oportunidade de desenvolver a intencionalidade educativa em uma relação dialógica entre os campos, a partir do "[...] acolhimento e da valorização dos interesses e curiosidades das crianças" (NATAL, 2017, p. 40).

Para tanto, o documento natalense destaca que os campos de experiências não estão centrados apenas na criança, tampouco nos professores, mas nas relações que ocorrem entre crianças, profissionais da educação, familiares, a comunidade, os saberes, as linguagens, o conhecimento e o mundo. O que difere do que diz o documento Campos de experiências: efetivando direitos e aprendizagens na educação infantilit ${ }^{16}$ que defende que os campos de experiências "[...] mudam o foco do currículo da perspectiva do professor para a da criança[..]" (BRASIL, 2018, p. 10). Nesse aspecto o documento de Natal reafirma sua intencionalidade em direcionar a Educação Infantil para as teorias da aprendizagem voltadas aos aspectos do desenvolvimento da criança presentes em Piaget, Vygotsky e Wallon.

O documento da capital potiguar destaca: a) a abordagem de Piaget, ao apresentar que o conhecimento pelo movimento (incluindo a dança) incorpora a gênese e o desenvolvimento nas interações com o meio; b) defende o sociointeracionismo de Vygotsky ao apresentar o movimento/dança como possibilidade de interação e comunicação como linguagem; c) valoriza Wallon ao explicar que é por meio do movimento que a criança inicia a conquista do universo que a cerca.

16 Essa publicação discute, expõe, problematiza e sugere maneiras de organizar as atividades pedagógicas nas unidades de Educação Infantil, considerando o conceito de campo de experiências proposto na Base Nacional Comum Curricular (Brasil, 2018). 
No que tange a organização para cada um dos cinco campos de experiência o documento de Natal apresenta os direitos de aprendizagem e desenvolvimento que devem ser garantidos às crianças. Estes são seguidos de quadros com propostas de ações pedagógicas e os objetivos de aprendizagem e desenvolvimento ${ }^{17}$. Os quadros de ações pedagógicas revelam como o professor pode garantir que os direitos e os objetivos sejam trabalhos. Isto é relevante à medida que o documento se apropria do que a BNCC prescreve e cria possibilidades de trabalho com intencionalidade pedagógica de acordo com o contexto da capital potiguar. Outra assimilação interessante é que as menções à Dança no documento de Natal aparecem destacada em três campos de experiências.

O primeiro, Corpo, gestos e movimentos, descreve que com o corpo as crianças exploram o mundo, dessa maneira interagem e "[...] produzem conhecimentos sobre si, sobre o outro, sobre o universo social e cultural, tornando-se, progressivamente, conscientes dessa corporeidade" (NATAL, 2017, p. 49). Além disso, focalizam na aquisição de repertório corporal por meio dos gestos e das linguagens.

Neste campo a Dança é mencionada nos direitos de: a) conviver com os outros pela gestualidade e cultura; b) participar de diversas atividades de cuidados pessoais e do contexto social; c) expressar corporalmente emoções, ideias e opiniões tanto nas relações do cotidiano quanto em manifestações artísticas e culturais. Os objetivos de aprendizagem e desenvolvimento que destacam a dança são apresentados para a pré-escola, estes reforçam dois objetivos da dança disposto na BNCC, a saber: expressão ${ }^{18}$ e criação ${ }^{19}$.

O curioso é que apesar de o documento apresentar objetivos de aprendizagem para a linguagem da Dança na pré-escola, não descreve as ações pedagógicas para tal. Por outro lado, no trabalho da creche não traz os objetivos de aprendizagem, mas exibem ações pedagógicas para a dança, entre elas o incentivo a vivências de danças circulares e atividades corporais, incluindo a dança, que promovam o desenvolvimento do equilíbrio, ritmo, resistência, velocidade, força e flexibilidade corporal.

O segundo, Traços, sons, cores e formas, valoriza a expressão e comunicação por meio de diversas linguagens. No texto de apresentação não há menções à dança, ela aparece nos direitos de: a) conviver e fruir das manifestações artísticas e culturais; b) explorar o uso de materiais, objetos e recursos tecnológicos para criar, apropriando-se de diferentes manifestações artísticas e culturais; c) expressar, com criatividade e responsabilidade, suas emoções, sentimentos, necessidades e ideias, por meio da dança e outras linguagens, compreendendo a comunicação com pares, professores e o meio; d) conhecer-se, no contato

17 Os quadros estão apresentados para a creche e para a pré-escola, diferentemente da Base que divide as crianças: em bebês, crianças bem pequenas e crianças pequenas.

18 Relacionado ao código da BNCC, representado pela sigla EI01CG01 e EI03CG01.

19 Relacionado ao código EI03CG03. 
criativo com manifestações artísticas e culturais locais e de outras comunidades, identificando e valorizando o seu pertencimento étnico-racial, de gênero e de crença religiosa, desenvolvendo sua sensibilidade, criatividade, gosto pessoal e modo peculiar de expressão, por meio das linguagens artísticas, entre elas a dança.

Os objetivos de aprendizagem e desenvolvimento relativos à linguagem da Dança estão divididos entre creche e pré-escola. Para a creche é proposto recriar danças, cenas de teatros, histórias, músicas. E como ações pedagógicas, sugerem: a) ampliação do repertório da criança a partir de músicas e danças da infância dos familiares, por meio da promoção de vivências lúdicas e invenções musicais; b) organização de ambientes, com a participação das crianças, para brincadeiras ou para ocasiões especiais, recriando danças, cenários, cenas teatrais, teatro de sombras, histórias e músicas. Para a pré-escola o objetivo é: analisar apresentações de teatro, música, dança, circo, cinema e outras manifestações artísticas, apresentando sua opinião verbal ou de outra forma. Para essa etapa o documento não propõe ações pedagógicas relacionadas à dança.

O terceiro campo que a dança aparece mencionada é Escuta, fala, pensamento e imaginação. Trata da aquisição de linguagem, potencializando a organização do pensamento e a participação da criança na cultura, por meio das interações, do faz de conta, da fruição literária em contação de história, leitura e encenação, entre outras. A dança está inserida nos direitos a) conviver com crianças e adultos e experimentar de múltiplas formas a gestualidade que marca sua cultura e presente nos cuidados pessoais; b) participar de diversas atividades de cuidados pessoais e do contexto social (de brincadeiras, encenações teatrais ou circenses, danças e músicas); c) expressar corporalmente, emoções, ideias e opiniões tanto nas relações cotidianas como nas brincadeiras, dramatizações, danças, músicas, contação de histórias, dentre outras manifestações, empenhando-se em compreender o que outros também se expressam. Nesse campo, não há indicações de objetivos de aprendizagem e ações pedagógicas que mencionem a dança.

Diante do exposto, entendemos que as proposições de Dança no documento de Natal pretendem valorizar o cuidado com o corpo, a ampliação do repertório de movimento e das manifestações artísticas e culturais, o ato motor, a criação e recriação de danças, a expressão de ideias e sentimentos e a fruição artística. Nesse sentido, o documento de Natal absorveu modificações advindas da BNCC no que tange sua organização, o reconhecimento das crianças como produtora de cultura, a identificação da dança como Arte, mas por outro lado, ainda valoriza os aspectos desenvolvimentista, funcionais e biologizantes como importantes para o aprendizado do movimento e da dança.

Reforçamos que a dança está para além dos aspectos da motricidade, a relação de cognição e da afetividade, ela é arte, conhecimento, manifestação cultural, que promove o contato da criança com sua sensibilidade artística, estética, expressiva e criativa. 
Cada um dos campos de experiência da BNCCEI do documento de Natal (RCMEI) expõe os objetivos de aprendizagem e desenvolvimento, estes se apresentam em níveis de progressão buscando a ampliação de dificuldades relacionadas à faixa etária. Nesse sentido, os objetivos dos documentos exploram de maneira generalista as possibilidades da experiência em dança. As menções à dança são rasas e resumidas, sem indicações claras de objetivos, saberes, conhecimentos, procedimentos e estratégias para realizar o trabalho.

Na mesma medida, os objetivos de aprendizagem da BNCC também são limitados diante de um documento que se propõe ser uma base para os currículos nacionais (ARCE; BALDAN, 2009). Isto posto, fica evidenciado que se a Base preconiza a construção do conhecimento levando em conta a inteireza da criança na integração das diferentes linguagens, entre as quais a dança, as indicações de conhecimentos sobre essa linguagem precisam de fato estar evidenciados em cada um dos direitos de aprendizagem e desenvolvimento, campos de experiências e objetivos. Esse caráter superficial em que os conhecimentos em Dança são apresentados pelos documentos nacionais acaba refletindo no RCMEI de Natal, que entre os objetivos de aprendizagem não trazem referências em relação aos conhecimentos específicos da Dança.

O que queremos ressaltar é que o documento nacional não aprofunda o trabalho com a linguagem da dança como conhecimento potente para a Educação Infantil. Advertimos que na medida em que a Dança não é valorizada em seus saberes na Base, por consequência não será mencionada nos documentos e muito menos efetivada nas práticas escolares por suas potencialidades artísticas/pedagógicas.

A ausência de menções nos demais campos de experiência pode prejudicar a inserção das práticas artísticas/pedagógicas em Dança nas unidades de Educação Infantil ou trazer propostas superficiais ou até mesmo não incluir a dança nas atividades cotidianas da criança por seu viés artístico. Esta insuficiência de informações reforça a dança a serviço de aquisição de habilidades e competências e/ou ilustração de festas escolares que esvazia essa linguagem em suas potencialidades artísticas/pedagógicas.

Nos questionamos como fortalecer a inserção dos conhecimentos em dança em articulação com as múltiplas linguagens da infância, se os conhecimentos mínimos sobre ela não estão evidenciados?

\section{Como seria se a dança permeasse toda a BNCCEI?}

Diante dos questionamentos apresentados pela leitura da BNCCEI e do RCMEI pensamos em como abrir um diálogo com a educação para a infância a fim de evidenciar conhecimentos em Dança nos documentos curriculares.

Dessa maneira, nessa última parte do texto apresentamos uma ideia de como os conhecimentos em Dança poderiam ser articulados aos direitos de aprendizagem e 
desenvolvimento, campos de experiência e objetivos de aprendizagem e desenvolvimento, presentes na Base.

Pensamos na perspectiva de estabelecer caminhos para que a dança chegue as escolas da infância, não temos a intenção de trazer fórmulas prontas, mas apresentar possibilidades para que nos currículos essa linguagem da arte esteja centrada na criança de cada contexto. Dessa maneira, cabe aos educadores da infância refinar esse olhar dançante para as crianças de cada grupo, entendendo e dialogando com suas especificidades. Isto faz parte de um processo, "[...] um convite a uma nova maneira de compreender a prática pedagógica como resultante de aprendizagens significativas não só para as crianças, mas também para o professor" (BRASIL, 2018, p. 11). Entendemos que o professor é o interlocutor, é alguém que participa do diálogo e organiza os tempos, espaços e materiais com intencionalidade pedagógica para que a experiência em dança aconteça. Isto é um chamamento para o adulto entrar no mundo da criança para compreendê-la, ouvi-la, recebêla a fim de proporcionar as experiências dançadas.

É sobre esse viés que evidenciamos que ao experienciar dança a criança pode: a) exercitar a imaginação em movimentos dançados; b) ressignificar o mundo por meio da sensibilização do corporal; c) investigar e construir conhecimentos sobre si, o outro e o ambiente que a rodeia; d) explorar e ter consciência do corpo, do espaço, das ações da gravidade, dos ritmos e tempos; e) experimentar-se como seres criativos criando as suas danças; f) expressar-se artisticamente; g) conhecer e entender a origem e os processos de criação das danças em seu contexto do mundo, entre outros.

Esses conhecimentos proporcionados pelo viés da dança devem ser desenvolvidos por meio dos eixos interações e a brincadeira, considerando as crianças não como receptoras, mas agentes participantes e produtores de cultura.

Outrossim, a linguagem da Dança a ser experienciada nos seis direitos de aprendizagem e desenvolvimento poderiam garantir as crianças: a) conviver com seus pares ampliando o repertório corporal sobre si e o outro, desenvolvendo o conhecimento a respeito das culturas, das danças regionais e do mundo; b) brincar com o corpo expandindo e diversificando o acesso as produções artísticos/culturais, construindo conhecimentos, trabalhando a imaginação, a criatividade por meio de jogos e brincadeiras dançadas ${ }^{20}$; c) participar na construção de diferentes formas de composição em dança, planejando todas as partes do processo de criação (escolha de temas, músicas, movimentos e figurinos junto a pares e educador; d) explorar e ter consciência das estruturas corporais e das

20 Gostaríamos de reforçar que os jogos e as brincadeiras podem se transformar em dança, a medida em que é direcionada a intencionalidade pedagógica. Isto é, depende de como a brincadeira é trabalhada, ela pode se transformar em dança. Para tanto, os professores precisam incluir as Temáticas da Dança (ANDRADE; GODOY, 2018) nos jogos e brincadeiras relacionando aos conhecimentos de corpo, fundamentos da dança (gravidade; relações espaciais; ritmo e tempo) e criação em dança. 
movimentações, dos movimentos artísticos, culturas e modos de criar danças; e) expressarse como seres criativos e sensíveis em danças coletivas e individuais, colocando suas ideias e pensamentos para dançar; f) conhecer-se sensivelmente pela movimento dançado.

Partindo do pressuposto que "[...] os campos não são trabalhados apenas em um dia definido da semana, nem há expectativa de haver uma aula de 45 minutos para o trabalho com um campo em cada dia ou para que determinado bimestre do ano letivo seja dedicado apenas a um campo" (BRASIL, 2018, p. 11), a dança poderia ser um integrador de algumas ações pedagógicas desenvolvidas na Educação Infantil.

Nesse sentido, a inserção dos conhecimentos em Dança no campo de experiência $O$ eu, o outro e o nós permitiria a criança ampliar os modos de relação com seus pares. $\mathrm{Na}$ medida em que a criança conhece a sua movimentação e as possibilidades de interação e sensibilização por meio do movimento dançado, ela pode alcançar os objetivos ${ }^{21}$ de: agir de maneira independente ao aprender sobre si mesma, reconhecendo suas estruturas corporais e modos de movimentação; valorizar sua identidade, criando danças individuais; demostrar empatia ao acolher as ideias de seus pares, trabalhando na criação de danças coletivas; comunicar seus sentimentos, desejos com movimentos dançados, entre outros.

No campo Corpo, gesto e movimento a criança pode por meio da linguagem artística da dança refinar seus movimentos, gestos, mímicas, posturas a fim de se comunicar e construir conhecimentos sobre si e sobre o universo social e cultural que a cerca. Ao trabalhar o conhecimento da dança por esse viés, a criança pode alcançar os objetivos de: transmitir sensações, emoções e sentimentos por meio do diálogo corporal que estabelecem dançando; refinar as habilidades corporais dançando e experimentando as ações da gravidade, equilíbrio e coordenação; entender os limites (entre ela e os outros) por meio da exploração e criação de movimentos dançados; criar danças por meio de jogos e brincadeiras que explorem estruturas corporais, espaço, tempo, peso, individualmente e coletivamente; explorar e improvisar danças que permitam experimentar o cuidado de si e do coletivo; criar danças por meio do faz de conta, de histórias, objetos inanimados, animais, ampliando seu universo simbólico, entre outros.

O campo Traços, sons, cores e formas traz as experiências voltadas para a expressividade das crianças, com a intenção de que a criança possa conviver com diferentes manifestações artísticas e culturais e dessa maneira vivenciar as mais variadas formas de expressão e linguagens artísticas. Outrossim, os conhecimentos em Dança nesse campo podem auxiliar a criança a atingir os objetivos de: desenvolver sensibilidade estética, por meio de diferentes criações artísticas integrando as linguagens da dança, teatro, música e artes

21 Para esse estudo apresentaremos os objetivos desejados para a dança, sem progressão por faixa etária, por entendermos que o olhar atento do professor pode estabelecer as progressões necessárias de acordo com cada criança e grupo. 
visuais; utilizar pausas, silêncios e sons em movimentos dançados; apreciar apresentações de diferentes tipos de danças a fim de fruir arte; explorar diferentes sons, ritmos, formas e dinâmicas de movimento por meio da dança; criar sonoridades, figurinos, cenários e objetos cênicos para os jogos e brincadeiras dançadas e para encenações criadas coletivamente; desenhar as formas geométricas no espaço com e no corpo por meio da dança; experimentar materiais que sensibilizem a criação para as danças, entre outros.

No campo Escuta, fala, pensamento e imaginação os conhecimentos em Dança podem valorizar o contato com a criação, imaginação, fruição, expressão na experiência da linguagem verbal em diálogo com outras linguagens artísticas. Dessa forma, a dança pode desenvolver os objetivos de: construir narrativas dançadas por meio do faz de conta e da contação de histórias; entender os processos de escuta por meio de danças feitas no coletivo; inventar brincadeiras, histórias e jogos a fim de estimular a construção de narrativas dançadas; representar, dramatizar e assumir papéis em brincadeiras dançadas; interpretar por meio do movimento dançado histórias conhecidas pelas crianças; improvisar com seus pares diferentes enredos dançados ligados as experiências cotidianas da criança.

No último campo de experiência, Espaços, tempos, quantidades, relações e transformações apresenta as diferentes dimensões de mundo em relação aos fenômenos naturais e socioculturais. Nesse campo, os conhecimentos em Dança podem ser potentes em estabelecer oportunidades para investigar as questões que as crianças formulam sobre o mundo e sobre si mesmas, dentro da perspectiva das noções de espaço, tempo, quantidade, relações e transformações a fim de estabelecer um olhar crítico e criativo sobre a vida. Dessa forma, a dança pode alcançar os objetivos de: reconhecer o espaço por meio do movimento dançado em direções, linhas, curvas, retas, altura (em cima, no meio e embaixo); identificar e experimentar diferentes ritmos das danças do mundo com a intenção de vivenciar diversas culturas; explorar e relatar os ambientes do cotidiano com danças em espaços pequenos e espaços abertos; identificar o ritmo (tempo) pessoal e do grupo nas danças; entre outros.

Dessa maneira, acreditamos que esta organização para os direitos, campos de experiência e objetivos de aprendizagem e desenvolvimento seja uma possibilidade para que os conhecimentos em Dança cheguem às escolas de educação infantil com suas potencialidades e intencionalidades artística/pedagógicas. Para isso faz-se necessária a inclusão desses conhecimentos nos documentos curriculares.

Por essa perspectiva salientamos que os conhecimentos em Dança na infância, ainda são pouco explorados por seu viés artístico/pedagógico, outrossim cabe uma ação conjunta entre educadores/artista da dança e profissionais da El no sentido de colaborar, conceber, revelar pressupostos e meios para que de fato essa linguagem esteja presente na El, para além da ilustração de festas escolares e da aquisição de habilidades e competências distantes da dança. 
Nesse sentido, nossa intenção foi abrir caminhos que permitam a construção de um diálogo entre os artistas/educadores/pesquisadores em dança com as escolas e secretarias de educação, no tocante a discussão de proposições para a dança por seu viés artístico/pedagógico em consonância com a BNCCEI.

Partimos da premissa de traçar um olhar para a infância a fim de favorecer, provocar, despertar o desejo de experimentação em dança com as crianças por meio dos documentos curriculares. Para além disso, o intuito foi sensibilizar os professores e dirigentes educacionais sobre as proposições artístico/pedagógicas da dança para a infância. Ademais oferecemos possibilidades de inserção da dança nos documentos em uma perspectiva dialógica em que os professores, ativem sua escuta, olhem, percebam e identifiquem nas crianças e no seu contexto caminhos possíveis para promover práticas pedagógicas autorais para a infância em que os conhecimentos em Dança sejam evidenciados.

\section{Referências}

ABRAMOWICZ, Anete; OLIVEIRA, Fabiana. A Sociologia da Infância no Brasil: uma área em construção. Educação (UFSM), Santa Maria, p. 39 - 52, 2010. Disponível em: https://periodicos.ufsm.br/reveducacao/article/view/1602/897. Acesso em: 03 ago. 2020.

ANDRADE, Carolina Romano de; GODOY, Kathya Maria Ayres de. Dança com crianças: propostas, ensino e possibilidades. Curitiba: Appris, 2018.

ARCE, Alessandra; BALDAN, Merilin. A criança menor de três anos produz cultura? Criação e reprodução em debate na apropriação da cultura por crianças pequenas. In: ARCE, A.; MARTINS, L. Ensinando aos pequenos de zero a três anos. Campinas: Alínea, 2009.

BARBOSA, Ana Mae. Redesenhando o desenho: educadores, política e história. São Paulo: Cortez, $2015 a$.

BARBOSA, Maria Carmen Silveira; RITCHER, Sandra Regina Simonis. Campos de Experiência: uma possibilidade para interrogar o currículo. In: FINCO, Daniela; BARBOSA, Maria Carmen Silveira; FARIA, Ana Lucia Goulart de (org.). Campos de experiências na escola da infância: contribuições italianas para inventar um currículo de Educação Infantil brasileiro. Campinas: Edições Leitura Crítica. 2015b. p. 185-198.

BRASIL. Campos de experiências: efetivando direitos e aprendizagens na educação infantil / [Ministério da Educação; texto final Zilma de Moraes Ramos de Oliveira]. São Paulo: Fundação Santillana, 2018.

BRASIL. Constituição da República Federativa do Brasil. Brasília: Senado Federal, 1988.

BRASIL. Lei Federal n. 8069, de 13 de julho de 1990. ECA - Estatuto da Criança e do Adolescente, Brasília: Senado Federal, 1990.

BRASIL. Ministério da Educação e do Desporto. Secretaria de Educação Fundamental. Referencial Curricular Nacional para a Educação Infantil /Ministério da Educação e do Desporto, Secretaria de Educação Fundamental. Vol.1. Brasília: MECISEF, 1998.

BRASIL. Ministério da Educação. Base Nacional Comum Curricular, MEC/CONSED/UNDIME NACIONAL, 2017.

BRASIL. Ministério da Educação. Secretaria de Educação Básica. Diretrizes curriculares nacionais para a educação infantil / Secretaria de Educação Básica. Brasília: MEC, SE, 2010. 
BROUGÈRE, Gilles. A criança e a cultura lúdica. In: KISHIMOTO, Tisuko (org.) O brincar e suas teorias. São Paulo: Pioneira, 2002.

BROUGÈRE, Gilles. Brinquedo e Cultura. São Paulo: Cortez, 1995. BROUGÈRE, Gilles. Les ludothèques face à l'objet jouet. In: Association des Ludothèques Françaises. Actes des universités d'été de L'Association des Ludothèques Françaises. Paris: Association des Ludothèques Françaises, 1998.

CORSARO, W.; EDER, D. Children's peer cultures. Annual Review of Sociology, 16, p. 197-220, 1990.

CORSARO, Willian. A. The Sociology of Childhood. 2. ed. London: Sage Publications, 2005a.

CORSARO, Willian. Entrada no campo, aceitação e natureza da participação nos estudos etnográficos com crianças pequenas. Educ. Soc., Campinas, vol. 26, n. 91, p. 443-464, Maio/Ago, 2005b.

FINCO, D.; BARBOSA, M. C. S.; FARIA, A. L. G. (org.). Campos de experiências na escola da infância: contribuições italianas para inventar um currículo de educação infantil brasileiro. Campinas: Leitura Crítica, 2015

International Project, n. 47, 1993, p. 11-18. Tradução de Maria Letícia Nascimento. Disponível em: http://www.scielo.br/scielo.php?script=sci arttext\&pid=S0103-73072011000100015\&lng=en\&nrm=iso. Acesso em: 15 jul. 2020.

LARROSA, Jorge Bondia. Linguagem e educação depois de Babel. Belo Horizonte: Autêntica, 2004.

LARROSA, Jorge Bondia. Notas sobre a experiência e o saber de experiência. Revista Brasileira de Educação, Rio de Janeiro, n. 19, jan-abr. 2002. Disponível em:

http://www.scielo.br/scielo.php?script=sci_arttext\&pid=S1413-24782002000100003\&lng=en\&nrm=iso. Acesso em: 29 mar. 2020.

LARROSA, Jorge Bondia. Pedagogia profana: danças, piruetas e mascaradas. 4. ed. Belo Horizonte: Autêntica, 2010.

MALAGUZZI, Loris. As Cem Linguagens da Criança. Bambini. Bergamo, Itália, n.2, Tradução livre do original italiano: Ana Lúcia Goulart de Faria, Maria Carmen Barbosa e Patrízia Piozzi. Fev. 1994.

MELLO, André da Silva et al. A educação infantil na Base Nacional Comum Curricular: pressupostos e interfaces com a Educação Física. Motrivivência, Florianópolis, v. 28, n. 48, p. 130-149, set. 2016. Disponível em: https://periodicos.ufsc.br/index.php/motrivivencia/article/view/21758042.2016v28n48p130. Acesso em: 01 ago. 2020.

NATAL. Secretaria Municipal de Educação. Referenciais Curriculares Municipais para a Educação Infantil de Natal - RN, Natal, 2017.

PIAGET, Jean. A construção do real na criança. Rio de Janeiro: Zahar; MEC, 1975.

PIAGET, Jean. A equilibração das estruturas cognitivas. Rio de Janeiro: Zahar, 1976.

PIAGET, Jean. Epistemologia genética. Petrópolis: Vozes, 1971.

PIAGET, Jean. Psicologia da criança. Rio de Janeiro: Diefel, 1978

PIAGET, Jean. Psicologia e pedagogia. Rio de Janeiro: Cia. Forense, 1970.

PROUT, Alan. Participação, políticas e as condições da infância em mudança. In: MÜLLER, Fernanda (org.). Infância em perspectiva: políticas, pesquisas e instituições. São Paulo: Cortez, 2010. Cap. 1.

QVORTRUP, Jens. Nove teses sobre a "infância como um fenômeno social". Eurosocial Report Childhood as a Social Phenomenon: Lessons from an

SARMENTO, Manuel Jacinto. Gerações e alteridade: interrogações a partir da sociologia da infância. Educ. Soc., Campinas, v. 26, n. 91, p. 361-378, ago. 2005. Disponível em: http://www.scielo.br/scielo.php?script=sci_arttext\&pid=S0100-15742001000100001\&lng=en\&nrm=iso. Acesso em: 05 jul. 2020 
SARMENTO, Manuel Jacinto. O Estudo de Caso Etnográfico em Educação. In: ZAGO, N.; PINTO DE CARVALHO, M.; VILELA, R. A. T. (org.). Itinerários de Pesquisa: Perspectivas Qualitativas em Sociologia da Educação. 2. ed. Rio de Janeiro: Lamparina, 2011. p. 137 - 179. Disponível em: http://repositorium.sdum.uminho.pt/bitstream/1822/36757/1/Etnografia.pdf. Acesso em: 05 jul. 2020.

SIROTA, Règine. Emergência de uma sociologia da infância: evolução do objeto e do olhar. Cadernos de Pesquisa, São Paulo: Fundação Carlos Chagas; Campinas: Autores Associados, n. 112, p. 7-31, mar. 2001.

VYGOTSKY, Lev Semionovitch. A formação social da mente. São Paulo: Martins Fontes, 1984.

VYGOTSKY, Lev Semionovitch. Pensamento e linguagem. Lisboa: Antídoto, 1979.

WALLON, H. Do acto ao pensamento. Lisboa: Moraes, 1979. 